Review article

\title{
Mirror therapy in post amputation patients with phantom limb pain: a mapping study
}

\author{
Jan Chrastina *, Hana Svízelová \\ Palacký University Olomouc, Faculty of Education, Institute of Special Education Studies, Olomouc, Czech Republic
}

\begin{abstract}
Objective: One of the complications in patients after limb amputation is phantom pain (PP) in the missing limb. Mirror therapy (MT) is a non-pharmacological approach to PP. The objective of the study is to describe and assess possible applications, effectiveness, practicability, and international experience with MT in patients with PP after limb amputation.

Methods: A descriptive mapping study that analyses, compares, and clusters the content of 22 relevant studies. The search was performed between 2000 and 2017 using the keywords and their combinations in the following databases: EBSCO, PsychINFO, PubMed, ProQuest, ScienceDirect, including metasearch engines.

Results: The specificities of PP after the application of MT in post amputation patients vary by the location of the amputated limb. MT alleviates PP in patients after amputation of the upper limb, lower limb, as well as in mixed groups (after amputation of the upper limb or lower limb); virtual MT is considered an alternative approach. MT remains a rather experimental therapeutic modality aimed at patients, where other attempts to alleviate PP have failed. Regarding the fact that MT is frequently modified and combined with other approaches (including various indications), the effectiveness of MT cannot be fully generalized. The main finding is the evidence of a short-term effect of MT on decreasing the intensity of PP.

Conclusions: Although MT is a relatively new phenomenon compared with other therapies, approaches and interventions, it is well known in foreign countries, and the range of indication is increasing. For MT to be generally spread and acknowledged, further research is needed together with a transfer of knowledge to teams providing comprehensive care to these patients. The outcomes of the mapping study will be used for a detailed analysis of the issue in the Czech Republic, where MT is used rarely and as an experimental additional therapy (particularly in occupational therapy).
\end{abstract}

Keywords: Amputation; Phantom pain; Phantom limb; Mapping study; Mirror therapy

\section{Introduction}

Mirror therapy (hereinafter referred to as "MT") is a therapeutic approach and a relatively new phenomenon in many research, scientific and especially clinical areas. It is still being developed and combined with other procedures, and the range of diseases, conditions and health problems/complications where the therapy is potentially successful is increasing. MT is often recommended for stroke patients and in post amputation patients with subsequent phantom pain. MT is also combined with a number of other autonomous and complementary therapies and approaches, or modified for example into virtual $M T$. The principle of MT is the use of visual feedback by means of a mirror located in front of the patient so that the affected (phantom) extremity is hidden behind the mirror and the reflection of the unaffected extremity simulates the movement of the affected extremity (Moseley et al., 2008). This tricks the brain and causes activation of the mirror neurons (Najiha et al., 2015). The existence of these neurons was proved for example by electroencephalography, magnetoencephalography, transcranial magnetic stimulation, positron emission tomography, or magnetic resonance. For the first time, mirror neurons were noticed in the observation of targeted movement of the hands of primates (macaques). Mirror neurons are present in multiple regions of the cortex; therefore, a commonly used term is the mirror neuron system (MNS). The entire system is active during the performance and observation of identical movements. Therefore, the system is indispensable in the process of learning by imitation, understanding other people's behaviour, understanding and interpretation of facial expressions, and the ability to empathise.

MT was described by V. S. Ramachandran and D. Rogers-Ramachandran in 1996 as a method of alleviating phantom pain perceived by patients in the amputated limb (Ramachandran and Rogers-Ramachandran, 1996; Ramadugu et al., 2017). This phenomenon is referred to as the phantom limb. The therapy is performed by means of mirrors, mirror glasses or mirror boxes - on one side there is a mirror and the limb is hidden in the box so that it is not visible. MT is a non-phar-

\footnotetext{
* Author for correspondence: Jan Chrastina, Palacký University Olomouc, Faculty of Education, Institute of Special Education Studies, Žižkovo náměstí 5, 77140 Olomouc, Czech Republic; e-mail: jan.chrastina@upol.cz http://doi.org/10.32725/kont.2019.012

Submitted: 2018-09-21 • Accepted: 2019-01-22 • Prepublished online: 2019-02-06 
macological alternative or complementary treatment strategy which is based on observation of the movements of the intact extremity in the mirror (Bowering et al., 2013). The basic mechanism of the effects is primarily related to the activation of the above mentioned mirror neurons in the premotor cortex of the lower frontal lobe, which are activated not only when a movement is performed but also when another person's movement is observed (Najiha et al., 2015). During MT the mirror is placed in the central sagittal plane to reflect the movements of the unaffected extremity (the patient is in a stable sitting position, ergonomic stable standing position, or is supported in case of instability). This creates a visual illusion and provides positive feedback to the motor cortex that the affected extremity moves (Bowering et al., 2013) - this is referred to as the mirror visual feedback (MVF). In order to make the mirror image as convincing as possible, the unaffected extremity or its part must be in the same visual condition as the affected or amputated extremity (part), e.g. sleeve, identical clothing of the same sleeve length and colour, etc. During MT the extremity moves and manipulates with objects - this is usually meaningful manipulation with ordinary objects (e.g. tooth brush, bunch of keys, mobile phone, etc.) However, in a group of patients with severe paresis, failure may be experienced which later impedes the course of MT; therefore, manipulative techniques are included in MT on a gradual basis. As a result of its simplicity, cost-efficiency and non-invasive nature, this approach becomes an attractive treatment of phantom pain in post amputation patients (Sütbeyaz et al., 2007). Ideally, the patient's unaffected extremity should be capable of physiological and pain-free range of motion. As has already been mentioned, this method was originally developed to decrease phantom pain in post amputation patients, and currently is also used in stroke patients, clients with cerebral palsy (referred to as "CP"), multiple sclerosis, complex regional pain syndrome (referred to as "CRPS"), in comprehensive rehabilitation of fractures and brachial plexus injuries (Grünert-Plüss et al., 2008; Najiha et al., 2015), and other issues.

Phantom pain is one of the most frequent complications in post amputation patients. This pain is perceived by patients in the missing limb (Desmond and MacLachlan, 2006), and may be of a continuous or intermittent nature. The missing limb (phantom limb) with phantom pain causes persistent sensory perceptions in patients after amputation and is a generally known but insufficiently understood phenomenon (Fraser et al., 2001). Patients do not perceive the phantom limb as their own and feel it in an unnatural position that distorts the body schema. Phantom pain in the phantom limb may be localized by patients in regions where they had previously suffered pain. Hunter et al. (2003) classify the phenomenon as follows: (a) presence of phantom limb - awareness of the missing limb; (b) phantom feelings, sensations - pain-free sensations such as heat, cold, pressure, itching, and tingling; (c) phantom pain - painful sensation in the missing limb. Phantom limb sensation, residual pain/residual limb pain and phantom limb pain $(P L P)$ are not unusual in post amputation clients. In the context of etiopathogenesis (central, peripheral and psychogenic mechanisms) and symptomatology of phantom pain, the following terms are also used: post amputation pain (PAP), neuropathic pain (NP), or stump pain.

Phantom pain may be present - regardless of the patient's age and gender and the location and type of amputation - in up to three quarters of patients soon after operation. It may take years, and is usually a very difficult symptom and annoying problem (Flor, 2008; Houghton et al., 1994), which has a negative effect on the quality of the patient's life, especially through fear, restricted mobility, distortion of the body schema, and a broad range of other implications (Flor, 2008). To achieve the greatest possible alleviation or elimination of phantom pain, surgical and pharmacological modalities are available including preventive, preoperative and early postoperative analgesics, acetaminophen, non-steroid antiphlogistics, opioids together with anticonvulsives and antidepressants (coanalgesics). The most frequent non-pharmacological procedures include transcutaneous electric nerve stimulation (TENS) and MT described in this study applied in patients with phantom pain perceived in the amputated limb (Ramadugu et al., 2017).

Using a mapping study design, the objective was to describe and assess the applications of mirror therapy, and its effectiveness, practicability and international experience in post amputation patients who feel phantom pain in the phantom limb.

\section{Materials and methods}

This is a descriptive study of a mapping study design. The intent of the research was to carry out a mapping study in order to identify and synthesize the evidence to achieve the objective of the study. The purpose of this design is to provide an overview of domains, themes and results of research activities in a predefined area that reflects the issue in question and the working research question.

During the initial stage of the methodology section the following research question was defined to be used in the subsequent search activities: "What findings have been published in international research studies about the practicability, effectiveness and experiences with the application of mirror therapy in post amputation patients who report phantom pain in the phantom limb?"

The fundamental search criteria included the availability of full-text versions of relevant documents, direct association with the defined research issue, successful reflection of the research question, and MT application in post amputation patients who reported the presence or perception of phantom pain in the phantom limb. The search procedure focused on available documents (studies) published between 2000 and 2017 (respecting the topicality requirement - studies not older than 10 years) in the English language. The documents that were only summaries, conference posters or papers without relevant full-texts in scientific journals were not accepted.

The following acceptance criteria were defined: studies that specify and describe the results, experiences with or effectiveness of MT application, and clearly define the target group of persons (post amputation patients with phantom pain in the phantom limb, irrespective of the reason for amputation), type and phase of amputation. Document criteria and types: empirical study (irrespective of scientific approach and study design) and review study (irrespective of methodology).

Rejection criteria included the following: focus on other aspects than the main issue (for example when MT was only referenced as a possible future therapy), focus on different target groups where health status was not clearly associated with amputation, patients who did not survive amputation (mostly traumatic), absence of results and associations concerning duality of MT + condition after amputation including phantom pain in the phantom limb, and failure to match the keywords or their combinations.

Relevant documents (studies) were obtained by searching available electronic bibliographical databases EBSCO, PsychINFO, PubMed, ProQuest, ScienceDirect, metasearch en- 
gine Discovery Service, and Google Scholar search engine and ResearchGate platform to identify relevant full-texts.

For the purposes of a systematic search the following keywords were used: mirror therapy, mirror box, mirror (box) therapy, mirror approach, amputation, removal, post amput patient/ client, phantom pain, phantom limb pain, phantom sensation, phantom extremity, postamputation pain, post amputation pain, residual pain and their combinations using Boolean operators. In the process of searching for studies (full-texts) and in this mapping study the terms patient - diseased - client - participant, and therapy - treatment - approach - method - procedure - experiment were considered synonyms. The findings were synthesised using an interpretative content analysis in line with the intent and objective of the review study. Due to a project carried by the authors (in 2017) and links to this study, the search procedure and processing of the mapping study did not include the results (studies) published in 2018.

The summary of documents included in the subsequent analysis included the selection (secondary) sample of documents. These were studies meeting the search criteria and acceptance/rejection criteria. At the same time, exact duplicates were excluded. During an analysis of documents in the selection sample those studies were rejected that did not focus on the issue in question or those that included only references to MT and its results concerning the target group of post amputation patients with phantom pain. Regarding the fact that the concept of the paper was not (see below) designed as a systematic/literary/narrative review or a mapping review but a mapping study, evidence levels were not considered. After analytical and systematic processing of the content of identified studies, a total of 33 relevant resources in English were identified of which the secondary (final) sample of 22 studies was used to produce the mapping study. However, some of the rejected studies were suitable for providing the background for MT and phantom pain on a generally applicable level. Processing of a mapping study is similar to an integrative review, but is not so strict concerning the search and analysis procedures compared with a systematic review/mapping review or scoping review (Armstrong et al., 2011). At the same time, it is not an umbrella study/umbrella review (Aromataris et al., 2015). The design of a mapping study does not necessarily require flowcharts or diagrams summarising the process of document (study) search and processing. The search of studies and analysis of findings was performed independently by both authors. Regarding the high agreement in the analyses of relevant studies by both authors, the agreement was mutually checked and subjected to critical evaluation. After that, relevant findings concerning the preparation of the mapping study were summarized. Mapping studies do not focus solely on the results of the studies identified, but also include critical assessment of other aspects of the issue that the reviewers consider relevant to the development of a comprehensive picture of the issue. Therefore, the mapping process focuses more on the associations and links within the issue (Cooper, 2016). The mapping study approach includes the processes of contextualization and conceptualization of the problem in the context of broader literary resources, and identification of possible gaps in the area. In this framework, the most significant contribution of the mapping study is to identify the need for further or follow-up studies (Cooper, 2016; Grant and Booth, 2009).

\section{Study/search limitations}

The authors are aware of the fact that not all relevant published studies might have been identified (as a result of the applied retrospective approach and non/availability of the outcomes in licensed databases). Another limitation considered by the authors is the fact that the paper includes the results of studies conducted in foreign countries. However, this limitation presents a challenge to enrich the Czech/Central European sociocultural environment with this specific therapy in post amputation patients with phantom pain. Another limiting factor could be searching for studies published only in English. Most studies were rather small concerning the number of participants, because more extensive or quantitative studies had not been performed and identified. A more extensive study could, through a static analysis, provide hard data that confirm the validity and conclusions.

\section{Results}

\section{Main domains of the mapping study}

The specificities of alleviating phantom pain in post amputation patients and the application of MT differ by the location of amputation and the amputated limb. Therefore, the main domains of the mapping study are presented as follows: (1) MT after upper limb amputation; (2) MT after lower limb amputation; (3) MT in mixed groups (i.e. after upper limb or lower limb amputation); (4) virtual mirror therapy in post amputation patients with phantom limb pain.

\section{Domain 1: Mirror therapy after upper limb amputation}

Ramachandran and Rogers-Ramachandran (1996) were the first to use MT to alleviate phantom pain. They called the new technique the Virtual Reality Box. The experiment involved ten participants who had undergone amputation of the upper limb (referred to as "UL"), including a patient who had been suffering from phantom pain for ten years. Immediately after application of MT, this participant reported almost immediate relief of pain, i.e. for the first time in the ten years of suffering from phantom pain. The authors demonstrated that visual feedback perceived through the intact limb allowed better control over the phantom limb, and relief of paralysis or spasm. A similar effect was also described by eight more patients out of the ten.

Wilcher et al. (2017) presented a case of a male patient (24 years of age) who had undergone a complete amputation of the left upper limb and arm as a result of a motorcycle accident. Phantom pain began to manifest, the man reported variable painful episodes ranging from 3 to 6 on a ten-point scale and lasting from 15 minutes to even more than 90 minutes. The patient reported burning, pain or convulsion, as if the missing limb was clenched. The average pain intensity ranged from 8 to 10 on a ten-point visual analogue scale (referred to as "VAS"). After two weeks of MT (15 minutes, at least two times a day) the patient reported decreased intensity of phantom pain. The maximum pain intensity on VAS was between 6 and 10. MT also included audio feedback. The participant's mother clapped her hands synchronously with the movement of her son's hand against the mirror, which provided both a visual and audio illusion of clapping.

Another study was conducted by Kim and Kim (2012). This also involved a young man (30 years of age), who had undergone a traumatic amputation of UL above the elbow eight months before the beginning of the case study. He complained about constant severe pain, convulsions in the missing limb and electrifying painful symptoms occurring once every few minutes. The patient also described a feeling as if the whole missing limb was in medial rotation. Despite the administration of analgesics, pain relief was insignificant and the patient still reported the degree of pain in the range from 8 to 10 on 
VAS. Other techniques such as blocking of the brachial plexus, subcutaneous ketamine infusions, etc., brought only a shortterm effect and therefore MT was applied. The patient came to take MT four times a week (15 minute therapeutic sessions). After a week of MT application the participant reported that he no longer felt the missing limb in medial rotation and the degree of pain on VAS decreased to 7. After a month of MT the convulsions disappeared and the degree of pain on VAS decreased to 5. After three months from the beginning of MT the patient continued at home three to four times a week. However, electrifying pain persisted and the average pain intensity was 4 . This case study confirmed significant relief from phantom pain after other methods such as medication, physiotherapy and neural blocking had failed.

An alternative MT application was used by Schmalzl et al. (2013) in six patients after UL amputation who had taken traditional MT with negligible or no effect. Therefore, they tried two experimental methods including visualization combined with an illusion of movement or touching the phantom limb. Three of the six participants had undergone UL amputation above the elbow, the remaining three under the elbow. Five amputations were traumatic, one as a result of a tumour disease. In each patient, detailed mapping of the stump was performed using systematic touching of the peripheral regions in order to precisely determine the triggers that cause phantom sensations. These locations on the stump were highlighted in colour. In the same way, the corresponding locations were marked on the intact limb. Before the experiment the participants were asked to assess pain intensity on VAS and the type of pain (e.g. convulsions, burning, tingling) felt on a typical day. The same assessment of pain was performed after the experiment. Each participant underwent one activity section and one "caressing" section. The activity section consisted of symmetrical movement of the intact and phantom limb in front of the mirror. During the "caressing" section two small brushes were used to simultaneously caress the highlighted locations on both extremities. During this procedure the participants were totally passive; they were asked not to perform or imagine any movement of the phantom limb. One patient did not have the locations highlighted; according to her, phantom pain was greatest in the palm of the phantom limb. Therefore, a brush was used to caress the palm of the intact limb and the centre location of the stump. The participants watched the caressing of the intact limb in the mirror; at the same time, identical locations were caressed on the phantom limb. During a control study the same procedure was performed but the mirror was covered with a cloth and the participants did not receive visual feedback from the intact limb. The results of the application of alternative MT did not confirm significant improvement in any of the patients in the activity section. On the contrary, three patients reported greater convulsions. Nevertheless, according to the results of the "caressing" section, five patients felt significant relief from pain during the section. However, in four of them the relief effect was very short (5 minutes). Only one participant reported relief from pain for a period of four hours.

Domain 2: Mirror therapy after lower limb amputation

MT of the lower limb (referred to as "LL") to alleviate phantom pain was first carried out by MacLachlan et al. (2004). This was a case study of a young man (32 years of age), who had undergone LL amputation as a result of necrotizing fasciitis. Phantom pain appeared two days after he gained consciousness. The pain always worsened in the course of the day - from feelings of being stung with needles and bearable pain to severe pain appearing late in the afternoon. Sometimes, overwhelming pain in the calf appeared. After unsuccessful pharmacological treatment and transcutaneous electrical neural stimulation, after which the patient complained about even greater pain, he was offered the application of MT. At the beginning the patient had a feeling of crossed fingers on the phantom limb and inability to control it. The worst phantom pain appearing in the afternoon was assessed from 5 to 9 on a ten-point scale, and stump pain from 0 to 2 . At the end of the third week of MT the patient no longer had feelings of crossed fingers on the missing limb, phantom pain was reported as zero and stump pain as 1 . The patient indicated a feeling of 25-30\% control over the phantom limb, but a feeling persisted that the phantom limb was somewhat shorter compared with the intact limb.

Another case study aimed at MT to alleviate phantom pain in LL was performed by Darnall (2009). This was MT conducted at home without direct professional supervision. The participant was given educational materials describing the application and effectiveness of MT (however, all of it related to UL amputation). Nevertheless, the participant was interested in the therapy and decided to try it out. The participant was a man (35 years of age), who had undergone LL amputation above the knee. Pharmacotherapy, physiotherapy and therapy by two psychologists did not improve the feelings of phantom pain; therefore, the participant decided to try out this experimental approach. During the therapy he moved the intact limb and watched the reflection in the mirror. He tried to include movements such as moving the foot up and down in the ankle, turning the ankle, touching the thumb, raising the whole leg and bending in the knee. At the beginning, this exercise was performed three times a week for 20-30 minutes, later the frequency was increased to 30 minutes a day. During the therapy the participant did not sense any phantom feelings and pain intensity decreased. After one month of therapy the participant indicated zero phantom pain (0/10), but stump pain persisted (3/10). The participant observed that when MT was skipped, phantom pain returned in one or two days, and therefore he decided even after three months (monitoring period) to continue in the therapy.

A randomized controlled trial involving 80 participants was published by Brodie et al. (2007). In the study, the patients were randomly divided into a "mirror group" (41 patients) and control group (39 patients). The purpose of the study was to determine the effect of observing LL reflection and repeated attempts to move the phantom limb and at the same time move the intact limb on phantom pain and phantom sensations (heat, coldness or itching). The "mirror group" was supposed to move the intact and phantom limb at the same time and watch the reflection of the intact limb. The control group was supposed to simply move both limbs. Both the "mirror" and control form of therapy were effective in decreasing the intensity and changing the nature of phantom sensations. However, compared with the control group, the "mirror" group did not show any additional benefits. In other words, watching the reflection of the intact limb and simultaneous movement of both (intact and phantom) limbs did not have a better effect on phantom pain (and sensations) compared with simple movements without watching the reflection. However, watching the reflection of the intact limb significantly increased the ability to control the phantom limb.

Similarly, Chan et al. (2007) performed a randomized controlled trial involving 18 patients aimed at the effect of LL mirror therapy on phantom pain. In addition to a "mirror" group and control group, a mental visualization group was formed. This group was supposed to close their eyes and imagine that they were moving the phantom limb. The patients in the mir- 
ror group attempted to move the amputated limb and watched the reflection of the intact limb. The control group performed the same but the mirror was covered with a cloth. The participants performed the therapy for 15 minutes a day. They recorded the number, duration and intensity of painful episodes on VAS. The initial values were similar in all groups. After four weeks of therapy all patients from the "mirror" group reported decreased pain, but in two patients this was only a shortterm effect lasting for several minutes. In the control group, only one patient reported decreased pain, while three patients complained about increased pain. In the mental visualization group two patients reported decreased pain, while four patients reported greater pain. The "mirror" group significantly differed from the remaining two groups and confirmed the effect of $M T$ on the reduction of phantom pain in $L L$.

Recently, another randomized controlled trial was performed by Pinto et al. (2016), the objective of which was to carry out a comparative analysis of the effectiveness of MT and transcranial direct current stimulation (tDCS) as tools to cope with phantom pain in LL. The recruitment procedure started in December 2015, and as of July 2016 (available information) it involved only one participant. The expected number of participants is 30 to 35 per year (132) and the authors expect the recruitment capacity to be reached during four years. After that the participants will be divided into four groups. The first group will take part in active MT and active tDCS, the second group will undergo simulated tDCS and active MT, the third group will be subject to active tDCS and simulated MT, and in the last group both therapies will be simulated (simulated MT and simulated tDCS).

Domain 3: Mirror therapy in mixed groups (i.e. after upper limb or lower limb amputation)

After the publication of a case study aimed at the effect of LL mirror therapy carried out in the patient's home environment and without professional supervision in order to cope with phantom pain (Darnall, 2009), the same author decided to carry out a pilot study of a similar nature. The participants of the study were patients with amputated LL or UL. Each of the 40 participants received a study file containing an information leaflet on MT, a diary for daily recordings, a mirror, and a DVD with a short MT tutorial, which contained information about how to adjust the mirror in order to hide the phantom limb behind it but to be able to see the reflection of the intact limb, etc. The participants were also given basic instructions (reserve 25 minutes a day for MT, find a comfortable position with the mirror, keep watching the mirror, move the intact limb gently in any way for a period of 25 minutes in a way to see two limbs, etc.) They were not instructed about attempting to move the phantom limb. Of the 40 registered participants, nine did not even start the treatment. The one-month therapy was completed by only 31 patients. The overall two-month treatment was completed by 26 patients. The results after one and after two months showed a significant decrease in phantom pain intensity. The median value representing the decrease in pain intensity after two months was $15.4 \%$. These results support the feasibility and the effectiveness of MT carried out in the home environment by the patient alone without professional therapist supervision, as suggested by Darnall and Li (2012).

Similarly, Yildırım and Kanan (2016) focused on MT performed by patients themselves without direct professional supervision. However, this was not MT in the home environment in the real sense of the word, because some patients underwent therapy in hospital (although they were instructed and supervised in the same way as patients at home). A total of 15 participants after amputation of LL or UL underwent practical MT training of about 40 minutes. Once the instructor was convinced about the participant's ability to perform MT correctly and independently, the patient was given a mirror (modified for LL or UL), practical MT guide, into which the participants were instructed to record pain intensity before and after therapy, and last but not least the duration of "exercising". The participants were supposed to record pain intensity on a scale from 0 to 10 . The patients were telephoned twice a week to answer any questions and to be encouraged in the exercise. After four weeks the guides were collected and those participants who wished to continue therapy kept the mirror. Most of the participants were after LL amputation (86.7\%) and reported being able to control the phantom limb. The most frequent type of pain was electrifying pain $(60 \%)$, followed by tingling (40\%). A total of $66.7 \%$ of the participants reported intermittent pain; the same proportion took analgesics. The results also suggested a statistically significant decrease in the average pain intensity during each week of the study as well as in the overall monthly score. Those patients who did not use any prostheses reported greater benefit of $M T$.

A study by Sumitani et al. (2008) focused not only on phantom pain but also neuropathic pain in patients after spinal cord injury, brachial plexus injury, and traumatic damage to the peripheral nerves, without using a control group. The study included participants after LL or UL amputation. The patients were asked to perform exercises with the unaffected extremity at their discretion (e.g. pulling, withdrawing, circling) for 10 minutes and to watch the reflection in the mirror. The overall length of the therapy was not identical for all participants; the average duration was 20.4 weeks. The results confirmed a short-term effect of MT consistent with the results by Darnall (2009). However, it was also confirmed that MT had a significant effect on decreasing deep pain.

\section{Domain 4: Virtual mirror therapy in post amputation patients} with phantom limb pain

Recently, an alternative to traditional MT appears to be its virtual modification. The first pioneers were Desmond et al. (2006) and Murray et al. (2007). Both teams published three case studies.

Desmond et al. (2006) used 3D projection of the arm on a computer screen. On the intact limb the participants had a wireless data glove, which transmitted information about the movements of the hand and fingers into the computer and at the same time an image was displayed on the screen. In this case, virtual MT was tested by two men after UL amputation and one woman after LL amputation. In each participant the assessment focused on the effects of traditional MT (i.e. with a mirror) and its virtual form during which the tasks were performed using the intact and phantom limb (holding hands, bending and tapping the forefinger, attempting to move all fingers simultaneously). In the first participant, greater effectiveness was observed in the case of traditional MT compared with the virtual version. However, even the virtual version had a relaxing and pain alleviating effect. The second participant reported zero changes in sensations or pain in the phantom limb for both types of therapy and did not learn to control the limb. After virtual MT, the last participant (woman after LL amputation) reported easier movement of the forefinger of the phantom limb, and could perform movements of the middle finger and ring finger, which she had been unable to do before.

Similar case studies were conducted by Murray et al. (2007), also involving three patients - two of them after UL amputation, one after LL amputation. During three weeks, 
the patients took two to five sessions of virtual MT. Compared with previous case studies however, traditional MT was not applied for the purposes of comparison. The approach was the IVR system (Immersive Virtual Reality), which transmits the movements of the intact limb to a virtual limb displayed in the area of the phantom limb. This was ensured by means of sensors attached to the joint of the elbow and wrist (in the case UL amputation) or to the knee and ankle (in the case of LL amputation). This virtual environment is represented by a room, which the participant sees from the perspective of a virtual figure. The participants used this system for a period of 30 minutes and were assigned various tasks: placing the virtual limb on coloured tiles which lit up in a specific sequence, striking or kicking a virtual ball, watching virtual movements, and directing virtual stimuli to a specific target. The first patient was a man after amputation of the UL above the elbow (almost 13 years ago). He had severe phantom pain 24/7 and never was without pain. He felt his missing limb was shorter than the intact limb, fixed in a position with the elbow bent at a right angle with the fingers in a grasping movement. During three weeks the patient underwent five sessions of MT. The second participant, a man after amputation of right LL below the knee (12 years of age), did not report as severe pain as the first patient, but also described it as a permanent and importunate feeling. The most painful were attacks of pain in the foot. This participant underwent three sessions of virtual MT. The third participant, a woman after amputation of left UL below the elbow, reported frequent phantom pain in the hand of the missing limb as incessant tingling of various intensities. She felt her phantom limb as immobile with clenched fingers and pain in the palm (feeling of nails digging into the palm). This patient underwent only two sessions of virtual MT. During all sessions, the first participant reported decreased pain, but pain returned after several hours. During the third session he had an intensive feeling of the phantom limb moving. In the following days however, the intensity of phantom pain increased again. In the case of the second participant, no consistent changes took place during the first two sessions. After the third session however, pain intensity decreased by 4 points (from 7 to 3 ) - during this session the participant did not use the prosthesis for the first time. The third participant in the study underwent only two sessions (the least of all), but reported radical changes after just the first session. She felt release of the clenched fingers and movements of the whole limb. In conclusion, it should be added that all three participating patients felt relief from pain during at least one session of virtual MT.

Virtual feedback was also analysed by Mercier and Sirigu (2009), but these authors used a slightly different method compared to Desmond et al. (2006) and Murray et al. (2007), who used sensors on the intact limb to create an image of a virtual limb. These authors recorded the movements of the intact limb. This video was then digitally reversed and shown on a computer screen. The image on the computer screen was then reflected in a mirror located in the place of the phantom limb. The research involved eight patients after amputation of UL or after trauma of the brachial plexus. The aim was to perform a detailed analysis of the effect of virtual training on alleviating phantom pain, and to provide more information about individual responses to this technique. Therefore, the case study design was used. Regarding the fact that most of the participants were able to control their phantom limb only to a limited extent, specific movements were selected for each participant in order to increase the probability of proper execution. Throughout the study, the difficulty of movements slightly increased. The length of each session was not dependent on time but on the number of movements. Each session contained 10 movements, which the patients were supposed to repeat ten times, i.e. in total one hundred movements. During each session the patients reported current pain intensity on VAS. Throughout the day they recorded pain intensity, number and duration of pain attacks and other useful aspects (e.g. weather changes, unusual activity, effect of negative emotions) that could have influenced pain. Eventually, all participants reported that movements of the phantom limb were easier with visual feedback. The greatest difference was reported by a patient who had felt his phantom limb as completely stiff for 13 years, but felt strong movement illusions during the therapy. Five of the eight patients reported pain decrease by 6 to $50 \%$ during the therapy. However, the remaining three patients reported pain increase by 10 to $51 \%$ during the therapy. Nevertheless, compared with the input data, in five patients a pain decrease of more than $30 \%$ was observed.

Ortiz-Catalan et al. (2014) published a case study, which was carried out using myoelectric activity of sensors attached to the stump, and producing an image of a virtual limb. A patient after amputation of UL in the elbow was able to perform movements and using a webcam and sensors saw an image of a virtual limb (the patient was also able to play a racing game). The patient underwent this procedure once a week for a period of 10 weeks. After four weeks the patient reported a period of decreased pain intensity. After ten weeks, pain-free periods appeared more often. Myoelectric activity sensors were also used in a virtual MT system called ViLimbs designed by Correa-Agudelo et al. (2015). The system is designed in a way that the patient stands in front of an immersive (curved) screen with a properly designed virtual 3D limb and tries to move the limb using myoelectric sensors on the stump and on the head. The virtual limb is created by means of a camera recording of the intact limb and using augmented reality. In addition to visual feedback, the texture of the virtual limb also receives pulses from the patient's forehead.

Bach et al. (2012) designed a new system of mixed reality in order to develop virtual MT. It consists of two cameras monitoring the patients' eyes, which in real time add an image of the missing limb (resembles goggles). However, the image is difficult to prepare due to modelling of a digital limb. This system had been introduced earlier (Bach et al., 2010) together with another virtual system for magnetic resonance imaging and a comparative study was announced but was not found. Later, Trojan et al. (2014) analysed the first introduced system (goggles) and its home use; this method was tested by six healthy participants who pretended they had an absence of an upper limb (attached to the body) and tried to perform various tasks (e.g. catching a ball). The results suggested gradual improvement in the participants' performance (after taking more lessons).

Regenbrecht et al. (2011) developed and tested a prototype of a mirror box virtual system. The box is fitted with cameras that monitor the movement of the limbs and an image of both limbs is created - both healthy and missing. According to the setting of the programme the virtual limb can move symmetrically or asymmetrically with respect to the intact limb. Then the authors carried out two non-clinical studies. In the first study, the virtual environment included a large ice cube or burning coal. This product was tested by a total of 32 participants (students who had no problems with mobility and the function of the upper extremities). 94\% of the participants did not recognize that one of their limbs was virtual, and considered it the image of their real limb. However, they did not indicate a significant difference in perceived temperature. In the 
second non-clinical study, real objects were used in addition to digital stimuli; the participants' hands were immersed in real water. Half of the participants were not aware that the image had changed compared with reality. After these two experiments, the authors carried out a case study, but with a patient suffering from the complex regional pain syndrome (CRPS); the therapy contributed to decreased pain.

A study aimed at improving a virtual MT system that included patients after amputation of LL was performed by Carrino et al. (2014). Most previous studies (Bach et al., 2012; Mercier and Sirigu, 2009; Ortiz-Catalan et al., 2014; Regenbrecht et al., 2011; Trojan et al., 2014) focused predominantly on patients after amputation of UL. They also tried to improve the technology of virtual MT to make it practicable in the home environment. They used a mixed reality environment (the patient sees the intact limb and at the same time a virtually developed limb in the place of the stump). In order to achieve better practicability in the home environment the authors used available devices such as (Xbox) Kinect to watch the intact limb and 3D animation of a model of the missing limb, head position sensor (in order to make an image from the right angle), and virtual goggles through which the patient watches everything. Similar to the systems by Regenbrecht et al. (2011), symmetrical or asymmetrical movement of the virtual limb can be set.

\section{Discussion}

The studies identified in the present research include a relatively "balanced" number of studies dealing with MT of the upper and lower limb or mixed groups of clients (some clients after amputation of the upper limb, some after amputation of the lower limb). MT only in UL was analysed by four studies (Kim and Kim, 2012; Ramachandran and Rogers-Ramachandran, 1996; Schmalzl et al., 2013; Wilcher et al., 2011) - studies of virtual MT and mixed studies are not included. Of the studies mentioned above, two were case studies (Kim and Kim, 2012; Wilcher et al., 2011). However, both confirmed a decrease in phantom pain as a result of MT. A study by Ramachandran and Rogers-Ramachandran (1996) in which MT was used for the first time, brought very promising results as one of the participants reported almost immediate relief from pain after almost ten years of suffering from phantom pain.

In a study by Schmalzl et al. (2013), the researchers decided to use an alternative form of MT including visualization combined with an illusion of movement or touching the phantom limb. In this case however, the authors did not achieve so much success (compared with previous studies mentioned above). Half of the patients reported worse convulsive feelings during the activity section; during the second section four out of six patients reported significant relief from pain, albeit very short (5 minutes). Only one participant reported relief for a period of four hours.

Studies dealing with MT aimed only at LL in post amputation patients again included case studies (Darnall, 2009; MacLachlan et al., 2004). In both cases, the results suggested a significant decrease in pain intensity. In a study by MacLachlan et al. (2004), a change in the phantom limb position was reported including a partial ability to control the phantom limb. Similarly, a randomized control trial by Brodie et al. (2007) concluded that watching the reflection of the intact limb significantly increased the ability to control the phantom limb. Chan et al. (2007) compared MT and the so-called mental visualization (participants close their eyes and imagine that they move the phantom limb) with a control group. In the control group, decreased pain was reported by only one patient, while three patients complained about increased pain. In the mental visualization group two patients reported decreased pain, while four patients reported greater pain. The "mirror" group significantly differed from the remaining two groups and confirmed the effect of MT on the reduction of phantom pain in LL.

Some studies combined patients with amputation of LL and UL (Darnall and Li, 2012; Sumitani et al., 2008; Yildırım and Kanan, 2016). The first study (Darnall and Li, 2012) focused on the application of MT in the home environment. A study by Sumitani et al. (2008) also included participants with other types of pain (neuropathic pain in patients after spinal cord injury, brachial plexus injury, and traumatic damage to the peripheral nerves). All of these studies brought positive results in the area of decreasing the intensity of phantom pain. Despite the fundamental advantages of MT, such as simplicity and financial accessibility, an increasing number of studies and scientists begin to focus on MT based on digital technologies (Bach et al., 2010; 2012; Carrino et al., 2014; Correa-Agudelo et al., 2015; Desmond et al., 2006; Mercier and Sirigu, 2009; Murray et al., 2007; Ortiz-Catalan et al., 2014; Regenbrecht et al., 2011).

The pioneers in this area were Desmond et al. (2006) and Murray et al. (2007), whose teams performed case studies using data gloves or sensors. In a study by Desmond et al. (2006), the first client reported greater effectiveness in the case of traditional MT compared with the virtual version. However, even the virtual version had a relaxing and pain alleviating effect. The second client reported zero changes in sensations or pain in the phantom limb for both types of therapy and did not learn to control the limb. After virtual MT, the third client reported easier movement of the forefinger of the phantom limb, and could perform movement of the middle finger and ring finger, which she had been unable to do before. Murray et al. (2007) concluded that all three patients felt relief from pain during at least one session of virtual MT. Mercier and Sirigu (2009), unlike other studies (Desmond et al., 2006; Murray et al., 2007), used a video of the intact limb in performing various movements. The video was then digitally reversed and presented on a computer screen.

The greatest difference was reported by a client who had felt his phantom limb as completely stiff for 13 years, but felt strong movement illusions during MT. Five of the eight patients reported pain decrease by 6 to $50 \%$ during the therapy. However, the remaining three patients reported pain increase by 10 to $51 \%$ during the therapy. Ortiz-Catalan et al. (2014) used sensors of myoelectric activity attached to the stump and subsequently created an image of a virtual UL. After four weeks the patient reported a period of decreased pain intensity; after ten weeks the period without pain occurred more often. Bach et al. (2012), Correa-Agudelo et al. (2015) and Regenbrecht et al. (2011) developed and tested virtual systems. Correa-Agudelo et al. (2015) and Ortiz-Catalan et al. (2014) used sensors of myoelectric activity for a system called ViLimbs. The system developed by Bach et al. (2012) consisted of two cameras "attached to" the patient's eyes in order to add the missing limb to the image in real time.

The team around Regenbrecht et al. (2011) developed and tested a prototype of a mirror box virtual system. The box is fitted with cameras that monitor the movement of the limbs and creates an image of both the healthy and missing limb. The system was first tested in two non-clinical studies followed by a case study involving a client with CRPS. Most studies (Bach et al., 2012; Mercier and Sirigu, 2009; Ortiz-Catalan et al., 
2014; Regenbrecht et al., 2011; Trojan et al., 2014) focused predominantly on patients after amputation of UL. The target group of persons only after amputation of LL was analysed by Carrino et al. (2014), who tried to improve virtual MT to make it practicable in the home environment of the client. For this purpose they developed a system that uses commonly available virtual reality devices.

A frequently mentioned problem associated with MT of clients with phantom pain was the short-term effect on decreasing pain intensity (Chan et al., 2007; Darnall, 2009; Kim and Kim, 2012; Schmalzl et al., 2013; Sumitani et al., 2008). It is therefore advisable to carry out MT regularly over a long period of time, ideally in the client's home environment after professional training.

\section{Conclusions}

Although MT, unlike other therapies, is a relatively new approach, internationally it is well-known and the area of indication of this highly specific therapy is still increasing. In the Czech Republic the area is not fully elaborated and MT is used occasionally as an experimental and complementary method.

MT is still considered an experimental type of treatment in clients where physiotherapeutic, pharmacotherapeutic and other approaches have failed. Regarding the fact that the therapy is frequently modified and combined with other approaches on various samples of patients (and various diseases), its effectiveness cannot be fully and positively generalized.

The main finding is the short-term effect of MT on decreasing the intensity of phantom pain. But the studies brought a number of significant results and their general recognition is subject to further research. In the area of alleviation of phantom pain, follow-up research is recommended in the monitoring of longterm alleviation from phantom pain. Regarding the absence of Czech studies, it would be desirable to perform research on the effect of MT on decreasing phantom pain in post amputation clients in the Czech Republic. Another potential application of MT is in patients with persisting acute pain and hypersensitivity, or for the purposes of improving the control of and getting accustomed to prostheses. As a result, MT should positively affect the degree of the patient's functional self-reliance (improvement of motor, sensory and coordination functions), increase in joint range, and improvement of body schema perception - all this with the highest possible degree of pain relief.
A challenge for a multidisciplinary team of professionals is to support the patient with an emphasis on MT application in the home environment (gradually the effect of MT disappears) and to observe effective continuity of the therapy while respecting the patients' intellectual needs (e.g. awareness of the definitive loss of the limb, gradual ability to look in the mirror, autotopagnosia - inability/impossibility to recognize and name own body parts, etc.). The possibility of mirror-based visual feedback may have a considerable potential in neurorehabilitation interventions and may support scientific, clinical and educational development. However, there may be a limitation on the part of the patients consisting in their inability to purchase an ergotherapeutic mirror for MT application (normally, these mirrors are self-developed).

Previously, a course on MT was organized in the Czech Republic (2016), during which the participants took a critical view of MT and its application in a broad spectrum of patients. One indication is repetitive strain injury (RSI), which is damage resulting from repeated strain, including for example tennis elbow or carpal tunnel syndrome. In the Czech Republic, MT is mostly used by occupational therapists in hand treatment. In the area of physiotherapy the frequency of MT use is extremely small. This can also be caused by ambiguous (valid) results and varying effectiveness of MT, which will always be affected by the patient's subjectivity. For these and other reasons, MT is so far not considered an autonomous therapeutic method in the Czech Republic or internationally.

\section{Conflict of interests}

The authors have no conflict to interests to disclose.

\section{Ethical aspects and conflict of interest}

The authors declare that the present study has no conflict of interest. The authors also declare that the text includes appropriate citations of all bibliographical sources.

\section{Acknowledgements}

The paper is part of the following project: Preparedness/readiness of residential social workers to manage difficult/crisis situations" - investigated in 2018 at the Faculty of Education, Palacký University Olomouc (Institute for Research and Development). 


\section{Zrcadlová terapie u pacientů s fantomovou bolestí po amputaci: mapping study}

\section{Souhrn}

Cíl: Jednou z komplikací u pacientů po amputaci končetin/y je fantomová bolest (FB) vnímaná v chybějící končetině. Zrcadlová terapie (ZT) je nefarmakologickým přístupem k FB a cílem studie je popsat a posoudit možnost využivání, efektivity, aplikovatelnosti a zahraniční zkušenosti se ZT u pacientů s FB po amputaci končetin/y.

Metodika: Deskriptivní mapping study analyzující, komparující a klastrující obsahy 22 dohledaných relevantních studií. Vyhledávání v rozmezí let 2000-2017 pomocí klíčových slov a jejich kombinací bylo provedeno v databázích EBSCO, PsychINFO, PubMed, ProQuest, ScienceDirect, včetně využití metavyhledávačů.

Výsledky: Specifika FB po aplikaci ZT u pacientů po amputacích se liší podle lokace amputované končetiny. ZT přináší (z)mírnění FB u pacientů po amputaci horní končetiny, dolní končetiny, stejně jako u smíšených skupin (po amputaci horní anebo dolní končetiny), a za alternativní přístup je považována ZT virtuální. ZT zůstává spíše experimentální modalitou terapie u pacientů, u kterých byly jiné postupy mírnící FB neúspěšné. Vzhledem $\mathrm{k}$ tomu, že dochází k modifikacím ZT a častým kombinacím s dalšími terapiemi (a u různých indikací), nelze dosud efektivitu ZT plně generalizovat. Dominantním zjištěním je doložení krátkodobého efektu ZT na snížení intenzity FB.

Závěr: Přestože je oproti dalším terapiím, přístupům a intervencím ZT poměrně novým fenoménem, v zahraničí je známá a stále se rozšiřuje okruh situací pro její indikování. K jejímu obecnému rozšíření a uznání je zapotřebí dalších výzkumů a transferu poznatků do týmů poskytujících komplexní péči těmto pacientům. Výstupy mapping study mohou být využity pro rozpracování tématu v podmínkách Ceské republiky, kde se ZT využívá ojediněle a jako experimentálně doplňková terapie (zejména v ergoterapii).

Klíčová slova: Amputace; Fantomová bolest; Fantomová končetina; Mapping study; Zrcadlová terapie

\section{References}

1. Armstrong R, Hall BJ, Doyle J, Waters E (2011). 'Scoping the scope' of a Cochrane review. J Public Health 33(1): 147-150. DOI: 10.1093/pubmed/fdr015.

2. Aromataris E, Fernandez R, Godfrey CM, Holly C, Khalil H, Tungpunkom P (2015). Summarizing systematic reviews: methodological development, conduct and reporting of an umbrella review approach. Int J Evid Based Healthc 13(3): 132-140. DOI: 10.1097/XEB.0000000000000055.

3. Bach F, Çakmak H, Maaß H (2012). Vision-based hand representation and intuitive virtual object manipulation in mixed reality. Biomed Tech 57(Suppl. 1). DOI: 10.1515/bmt2012-4086.

4. Bach F, Schmitz B, Maaß H, Çakmak H, Diers M, Bodmann RB, Kamping S, Flor H (2010). Using Interactive Immersive VR/AR for the Therapy of Phantom Limb Pain. In: Klyuev VV, Cohen M (Eds). Proceeding HC '10 Proceedings of the 13th International Conference on Humans and Computers. Fukushima-ken: University of Aizu Press, pp. 183-187.

5. Bowering KJ, O'Connell NE, Tabor A, Catley MJ, Leake HB, Moseley GL, Stanton TR (2013). The effects of graded motor imagery and its components on chronic pain: a systematic review and meta-analysis. J Pain 14(1): 3-13. DOI: 10.1016/j. jpain.2012.09.007.

6. Brodie E, Whyte A, Niven CA (2007). Analgesia through the looking-glass? A randomized controlled trial investigating the effect of viewing a 'virtual' limb upon phantom limb pain, sensation and movement. Eur J Pain 11(4): 428-436. DOI: 10.1016/j.ejpain.2006.06.002.

7. Carrino F, Rizzotti D, Gheorghe C, Kabasu Bakajika P, Francescotti-Paquier F, Mugellini E (2014). Augmented reality treatment for phantom limb pain. In: Shumaker R, Lackey $S$ (Eds). Virtual, augmented and mixed reality. Applications of virtual and augmented reality: 6th International conference, VAMR 2014, Heraklion, Crete, Greece, June 22-27.

Proceedings, Part II. Switzerland: Springer International Publishing, pp. 248-257.

8. Chan BL, Witt R, Charrow AP, Magee A, Howard R, Pasquina PF, et al. (2007). Mirror therapy for phantom limb pain. New England Journal of Medicine 357(21): 2206-2207. DOI: 10.1056/NEJMc071927.
9. Cooper D (2016). What is a 'mapping study?' J Med Lib Assoc 104(1): 76-78. DOI: 10.3163/1536-5050.104.1.013.

10. Correa-Agudelo EA, Hernandez M, Ferrin C, Gomez JD (2015). ViLimbs: Improving Phantom Limb Treatment Through Multisensory Feedback. In: Inkpen K, Woo W. (Eds). Proceedings of the 33rd Annual ACM Conference Extended Abstracts on Human Factors in Computing Systems. New York: ACM Press, pp. 1313-1318.

11. Darnall BD (2009). Self-delivered home-based mirror therapy for lower limb phantom pain. Am J Phys Med Rehabil 88(1): 78-81. DOI: 10.1097/PHM.0b013e318191105b.

12. Darnall BD, Li H (2012). Home-based self-delivered mirror therapy for phantom pain: A pilot study. J Rehabil Med 44(3): 254-260. DOI: 10.2340/16501977-0933.

13. Desmond DM, MacLachlan M (2006). Affective distress and amputation-related pain among older men with long-term, traumatic limb amputations. J Pain Symptom Manage 31(4): 362-368. DOI: 10.1016/j.jpainsymman.2005.08.014.

14. Desmond DM, O’Neill K, de Paor A, McDarby G, MacLachlan $M$ (2006). Augmenting the reality of phantom limbs: three case studies using an augmented mirror box procedure. J Prosth Orthot 18(3): 74-79. DOI: 10.1097/00008526-20060700000005.

15. Flor H (2008). Maladaptive plasticity, memory for pain and phantom limb pain: review and suggestions for new therapies. Expert Rev Neurother 8(5): 809-818. DOI: $10.1586 / 14737175.8 .5 .809$.

16. Fraser CM, Halligan PW, Robertson IH, Kirker SG (2001). Characterizing phantom limb phenomena in upper limb amputees. Prost Orthot Int 25(3): 235-242. DOI: $10.1080 / 03093640108726607$.

17. Grant MJ, Booth A (2009). A typology of reviews: an analysis of 14 review types and associated methodologies. Health Inf Libr J 26(2): 91-108. DOI: 10.1111/j.1471-1842.2009. 00848.x.

18. Grünert-Plüss N, Hufschmid U, Santschi L, Grünert J (2008). Mirror therapy in hand rehabilitation: a review of the literature, the St Gallen Protocol for mirror therapy and evaluation of a case series of 52 patients. J Hand Ther 13(1): 4-9. DOI: $10.1177 / 175899830801300101$.

19. Houghton AD, Nicholls G, Houghton AL, Saadah E, McColl L (1994). Phantom pain: natural history and association with rehabilitation. Ann R Coll Surg Engl 76: 22-25. 
20. Hunter JP, Katz J, Davis KD (2003). The effect of tactile and visual sensory inputs on phantom limb awareness. Brain 126(3): 579-589. DOI: 10.1093/brain/awg054.

21. Kim SY, Kim YY (2012). Mirror therapy for phantom limb pain. Korean J Pain 25(4): 272-274. DOI: 10.3344/ kjp.2012.25.4.272.

22. MacLachlan M, McDonald D, Waloch J (2004). Mirror treatment of lower limb phantom pain: A case study. Disabil Rehabil 26(14-15): 901-904. DOI: 10.1080/09638280410001708913.

23. Mercier C, Sirigu A (2009). Training with virtual visual feedback to alleviate phantom limb pain. Neurorehabil Neural Repair 23(6): 587-594. DOI: 10.1177/1545968308328717.

24. Moseley GL, Gallace A, Spence C (2008). Is mirror therapy all it is cracked up to be? Current evidence and future directions. Pain 138(1): 7-10. DOI: 10.1016/j.pain.2008.06.026.

25. Murray CD, Pettifer S, Howard T, Patchick EL, Caillette F, Kulkarni J, Bamford C (2007). The treatment of phantom limb pain using immersive virtual reality: Three case studies. Disabil Rehabil 29(18): 1465-1469. DOI: 10.1080/09638280601107385

26. Najiha A, Alagesan J, Rathod VJ, Paranthaman P (2015). Mirror therapy: a review of evidences. Int J Physiother Res 3(3): 1086-1090. DOI: 10.16965/ijpr.2015.148.

27. Ortiz-Catalan M, Sander N, Kristoffersen MB, Håkansson B, Brånemark R (2014). Treatment of phantom limb pain (PLP) based on augmented reality and gaming controlled by myoelectric pattern recognition: a case study of a chronic PLP patient. Front Neurosci 8: 24. DOI: 10.3389/fnins.2014.00024.

28. Pinto C, Saleh Velez F, Bolognini N, Crandell D, Merabet LB, Fregni F (2016). Optimizing rehabilitation for phantom limb pain using mirror therapy and transcranial direct current stimulation: A randomized, double-blind clinical trial study protocol. JMIR Res Protoc 5(3): e138. DOI: 10.2196/ resprot.5645.
29. Ramachandran VS, Rogers-Ramachandran D (1996). Synaesthesia in phantom limbs induced with mirrors. Proc Biol Sci 263(1369): 377-386. DOI: 10.1098/rspb.1996.0058.

30. Ramadugu S, Nagabushnam SC, Katuwal N, Chatterjee K (2017). Intervention for phantom limb pain: A randomized single crossover study of mirror therapy. Indian J Psychiatry 59(4): 457-464. DOI: 10.4103/psychiatry. IndianJPsychiatry_259_16.

31. Regenbrecht H, McGregor G, Dixon B., Hoermann S (2011). From mirror therapy to augmentation. Information Science Discussion Papers Series 2011(08): 1-16.

32. Schmalzl L, Ragnö Ch, Ehrsson HH (2013). An alternative to traditional mirror therapy. Clin J Pain 29(10): 10-18. DOI: 10.1097/AJP.0b013e3182850573.

33. Sumitani M, Miyauchi S, McCabe CS, Shibata M, Maeda L, Saitoh Y, et al. (2008). Mirror visual feedback alleviates deafferentation pain, depending on qualitative aspects of the pain: a preliminary report. Rheumatology (Oxford) 47(7): 1038-1043. DOI: 10.1093/rheumatology/ken170.

34. Sütbeyaz S, Yavuzer G, Sezer N, Koseoglu BF (2007). Mirror therapy improves hand function in subacute stroke: a randomized controlled trial. Arch Phys Med Rehabil 88(5): 555-559. DOI: 10.1016/j.apmr.2007.02.034.

35. Trojan J, Diers M, Fuchs X, Bach F, Bekrater-Bodmann R, Foell J, et al. (2014). An augmented reality home-training system based on the mirror training and imagery approach. Behav Res Methods 46(3): 634-640. DOI: 10.3758/s13428-013-0412-4.

36. Wilcher DG, Chernev I, Yan K (2011). Combined mirror visual and auditory feedback therapy for upper limb phantom pain: a case report. J Med Case Reports 5(1): 1-4. DOI: 10.1186/17521947-5-41.

37. Yildırım M, Kanan N (2016). The effect of mirror therapy on the management of phantom limb pain. Ağr 28(3): 127-134. DOI: 10.5505/agri.2016.48343. 